\title{
BIOCHEMICAL PROFILE OF GREEN AND RED ALGAE - A KEY FOR UNDERSTANDING THEIR POTENTIAL APPLICATION AS FOOD ADDITIVES
}

\author{
Iv. Vasileva*, J. Ivanova \\ Experimental Algology, Institute of Plant Physiology and Genetics, Bulgarian Academy of Sciences, \\ Sofia, Bulgaria
}

\begin{abstract}
PURPOSE: With the improvements of the microalgal cultivation industry, it became possible to add algal biomass and its metabolites in foods in order to create a balanced and health-food. METHODS: By determining the growth and the biochemical composition (lipids, carbohydrates and proteins), two algal strains were evaluated as a potential source of food additives - the newly isolated strain of the green algae Scenedesmus sp. and the red algae Porphyridium cruentum). RESULTS: It turned out that in Scenedesmus sp. BGP the most abundant component were the proteins (up tp $45 \%$ ), which makes this alga an excellent unconventional protein producer. As opposed to it, the biochemical composition of Porphyridium cruentum was dominated by carbohydrates (up to 57\%), but there was also a high content of some essential polyunsaturated fatty acids: arachidonic (AA, 20:4; 13-29\%) and eicosapentaenoic acid (EPA, 20:5, 24-25\%). CONCLUSIONS: Microalgae are a really remarkable source of biomass and a wide range of substances, but this area is poorly explored. Both of the microalgal strains proved to be important sources of functional ingredients that could be successfully used as food additives together or separately.
\end{abstract}

Key words: Scenedesmus, Porphyridium, protein, carbohydrate, arachidonic acid, eicosapentaenoic acid

\section{INTRODUCTION}

Microalgae have been used for a long time as food for humans and for animals in aquaculture. With the increasing of world's population and predictions of an insufficient protein supply, in the early 1950's started a search for new alternative and unconventional protein sources. Algal biomass proved to be a good candidate for this purpose. Due to their relatively simple morphological organization, fast growth, high productivity and enormous and diverse biosynthetic potential, microalgae became desirable research objects. Improvements in the microalgal biotechnology give opportunity to add microalgal biomass and its metabolites in foods in order to create balanced and health-food (1). Microalgae for

*Correspondence to: Ivanina Vasilevap address: Acad. G. Bonchev Str., bldg. 21, 1113, Sofia, Bulgaria, fax: +3592 8739952, e-mail: ivanina_vasileval@abv.bg human nutritional needs are currently being manufactured in different forms such as tablets, capsules, pastilles, liquids and nutritional supplements and are also incorporated into snacks, pastas, candy bars or chewing gum and in beverages $(1,2)$.

Microalgal biomass consists of different nutritional components of which the main three are proteins, carbohydrates and lipids. Some of the reasons why microalgae came to be of a such commercial importance in relation to its nutritional composition are presented in this article. The presence of high protein content in microalgae is the main reason why it should be kept in mind as an unconventional source of protein. Their amino acid pattern compares favorably with other foods. Carbohydrates are obtained in various forms such as starch, glucose, sugars, other polysaccharides. This fact explains why there are no limitations to its use in food and animal feed $(3,4)$. 
Scenedesmus sp. is particularly found to contain all essential amino acids and a good amount of protein, lipid and essential minerals (5). According to (3) and (6), Scenedesmus contains lipids, proteins and carbohydrates that can compare favorably with the traditional sources (Table 3).

Scenedesmus is among the most used microalgae (without any toxic impacts or abnormalities in experiments with test animals) that has attracted the attention of manufacturers in the food and health-food market (7). Another promising microalga for commercial purposes is the unicellular red alga Porphyridium cruentum (Rhodophyta). This alga has spherical cells that lack a cell wall and instead it has a polysaccharide capsule (8). This feature helps its assimilation by the animals and humans. The red microalgal polysaccharides exhibit various bioactivities that have nutritional, medical, and cosmetic significance. Animal feeding experiments have shown that rodents whose diets are supplemented with low concentrations of red microalgal polysaccharides have considerably lowered levels of serum cholesterol, triglycerides, and low-density lipoprotein levels $(9,10)$ with no evidence of toxic side effects. This strain is a potential source for several products, such as lipids (11), pigmens (7) and carbohydrates (12). Only plants and microalgae are able to synthesize essential $\omega$ -
VASILEVA IV., et al. 3 and $\omega-6$ essential PUFA. Therefore, microalgae supply entire food chains with these vital components. One of the innovative approaches is the preparation of eicosapentaenoic acid (EPA) and arachidonic acid (AA) from microalgae (like Porphyridium sp.) for baby food and the health food market (13).

The aim of the study was to prove the suitabily of the two algal strains as sources of functional ingredients by determining their biochemical composition. The high protein content of Scenedesmus sp. BGP and the production of polyunsaturated fatty acids by Porphyridium cruentum are the characteristics that reveal the potential of the strains as food additives.

\section{MATERIALS AND METODS}

Algal material and cultivation conditions Scenedesmus sp. strain BGP (Chlorophyta) was isolated from a rainwater puddle (Sofia, Bulgaria). Monoalgal, non-axenic cultures of Scenedesmus sp. BGP were grown autotrophically on $1 / 4$ medium of (14), modified by (15) (Table 1). The red microalga Porphyridium cruentum (Rhodophyta), strain VISCHER 1935/107 was acquired from the culture collection of the Institute of Botany, Trebon, Czech Republic and was grown on the modified culture medium of (16) (Table 2).

Table 1. Composition of the modified nutritive medium, used for cultivation of Scenedesnus sp. BGP.

\begin{tabular}{|c|c|}
\hline Elements & {$[\mathbf{m g} / \mathbf{l}]$} \\
\hline $\mathrm{NH}_{4} \mathrm{NO}_{3}$ & 400 \\
\hline $\mathrm{CO}\left(\mathrm{NH}_{2}\right)_{2}$ & 300 \\
\hline $\mathrm{KH}_{2} \mathrm{PO}_{4}$ & 170 \\
\hline $\mathrm{MgSO}_{4} .7 \mathrm{H}_{2} \mathrm{O}$ & 494 \\
\hline $\mathrm{CaCl}_{2} .2 \mathrm{H}_{2} \mathrm{O}$ & 5.478 \\
\hline $\mathrm{H}_{3} \mathrm{BO}_{3}$ & 1.545 \\
\hline $\mathrm{CuSO}_{4} .5 \mathrm{H}_{2} \mathrm{O}$ & 0.623 \\
\hline $\mathrm{Fe}_{2}\left(\mathrm{SO}_{4}\right)_{3} .9 \mathrm{H}_{2} \mathrm{O}$ & 7.025 \\
\hline $\mathrm{MnSO}_{4} \cdot 4 \mathrm{H}_{2} \mathrm{O}$ & 0.558 \\
\hline $\mathrm{ZnSO}_{4} .7 \mathrm{H}_{2} \mathrm{O}$ & 0.718 \\
\hline $\mathrm{CoSO}_{4} .7 \mathrm{H}_{2} \mathrm{O}$ & 0.703 \\
\hline$\left(\mathrm{NH}_{4}\right)_{2} \mathrm{MoO}_{4} .7 \mathrm{H}_{2} \mathrm{O}$ & 0.605 \\
\hline $\mathrm{NaHCO}_{3}$ & 2000 \\
\hline
\end{tabular}


VASILEVA IV., et al.

Table 2. Composition of the modified nutritive medium, used for cultivation of Porhyridium cruentum

\begin{tabular}{|c|c|}
\hline Macroelements & {$[g / l]$} \\
\hline $\mathrm{KH}_{2} \mathrm{PO}_{4}$ & 0.8 \\
\hline $\mathrm{KNO}_{3}$ & $\frac{1}{1}$ \\
\hline $\mathrm{NaCl}$ & 27 \\
\hline $\mathrm{MgSO}_{4} \cdot 7 \mathrm{H}_{2} \mathrm{O}$ & 6.6 \\
\hline $\mathrm{MgCl}_{2} \cdot 6 \mathrm{H}_{2} \mathrm{O}$ & 5.6 \\
\hline $\mathrm{CaCl}_{2} \cdot 2 \mathrm{H}_{2} \mathrm{O}$ & 1.5 \\
\hline $\mathrm{NaHCO}_{3}$ & 0.04 \\
\hline Microelements & {$[\mathrm{mg} / \mathbf{1 0 0 m l}]$} \\
\hline $\mathrm{ZnCl}_{2}{ }^{*}$ & 4 \\
\hline $\mathrm{H}_{3} \mathrm{BO}_{3} *$ & 60 \\
\hline $\mathrm{CoCl} .6 \mathrm{H}_{2} \mathrm{O}^{*}$ & 1.5 \\
\hline $\mathrm{CuCl} .2 \mathrm{H}_{2} \mathrm{O}^{*}$ & 4 \\
\hline $\mathrm{MnCl}_{2} .4 \mathrm{H}_{2} \mathrm{O}^{*}$ & 40 \\
\hline$\left(\mathrm{NH}_{4}\right)_{6} \mathrm{Mo}_{7} \mathrm{O}_{24 .} 4 \mathrm{H}_{2} \mathrm{O}^{*}$ & 37 \\
\hline $\mathrm{FeCl}_{3} \cdot 4 \mathrm{H}_{2} \mathrm{O}^{* *}$ & 240 \\
\hline
\end{tabular}

*All the components are dissolved in $100 \mathrm{ml} \mathrm{dH}_{2} \mathrm{O} .1 \mathrm{ml}$ of the solution is added to $1 \mathrm{~L}$ medium.

** Dissolved in $100 \mathrm{ml}$ of $0.05 \mathrm{M} \mathrm{Na}_{2}$ EDTA. $1 \mathrm{ml}$ of the solution is added to $1 \mathrm{~L}$ medium.

The experiments were carried out on a specially equipped block. The cultures, in 200 $\mathrm{ml}$ flasks, were continuously supplied with carbon dioxide (2\% in air) at a constant temperature (about $24^{\circ} \mathrm{C}$ ) and illumination 8000 lux. Initial culture densities of $\sim 0.6 \mathrm{~g} / \mathrm{l}$ and $\sim 0.8 \mathrm{~g} / \mathrm{l}$ was used for all the treatments of Scenedesmus sp. BGP and Porphyridium cruentum, respectively. To analyze the biochemical composition, experimental cultures were harvested in both exponential and stationary growth phase. Cells were collected by centrifugation $(5000 \times \mathrm{g}, 20 \mathrm{~min})$, rinsed three times with water, frozen, and stored at $-70^{\circ} \mathrm{C}$. The concentration of the dried algal biomass (dry weight, DW) was determined gravimetrically. The growth of Scenedesmus and Porphyridium was evaluated by the increase in the DW. The protein content was measured according to the method of (17). The lipid content was determined after extraction with a mixture of methanol and chlorophorm (18). The carbohydrates were quantified using the phenol-sulfuric acid method of (19). The viscosity of the culture's supernatant indicated the amount of extracellular polysaccharide synthesized. It was measured by a viscosimeter B3 (VEB MLW, DDR). The algal culture was centrifuged for $30 \mathrm{~min}$. at $8000 \mathrm{~g}$ and the cells were removed. The supernatant's viscosity was determined by the following formula:

$$
\eta=t(Q 1-Q 2) K
$$

where $\eta$ is the dynamic viscosity of the liquid (mPa.s); $\mathrm{t}$ - the time for the ball to fall in the viscosimeter; $\mathrm{Q}_{1}$ - ball density; $\mathrm{Q}_{2}$ - density of the studied liquid, $\mathrm{K}$ - ball constant (m Pa.cm ${ }^{3 /}$ g).

All experiments were conducted in three repetitions.

\section{RESULTS}

Growth Porphyridium cruentum is easily cultivated in an artificial seawater medium. The green algae of genus Scenedesmus are commonly found in fresh waters. Both strains are very suitable producers of biomass as they have a high tolerance towards variation of the most important environmental factors such as light intensity, temperature, $\mathrm{pH}$, as well as the content of the nutrient medium (20). The cultivation time is an important factor for increasing the biomass concentration (11). The growth curves of Porphyridium cruentum displayed the expected characteristics with a lag phase during the first one or two days, an exponential growth phase till the $120^{\text {th }} \mathrm{h}$., and stationary phase when growth reached it maximal value (Figure 1). The peak of the cell concentration of the Porphyridium cruentum culture was reached on the $144 \mathrm{~h}$. The microalgal biomass increased from 0.8 to 5.15 $\mathrm{g} / \mathrm{l}$. 


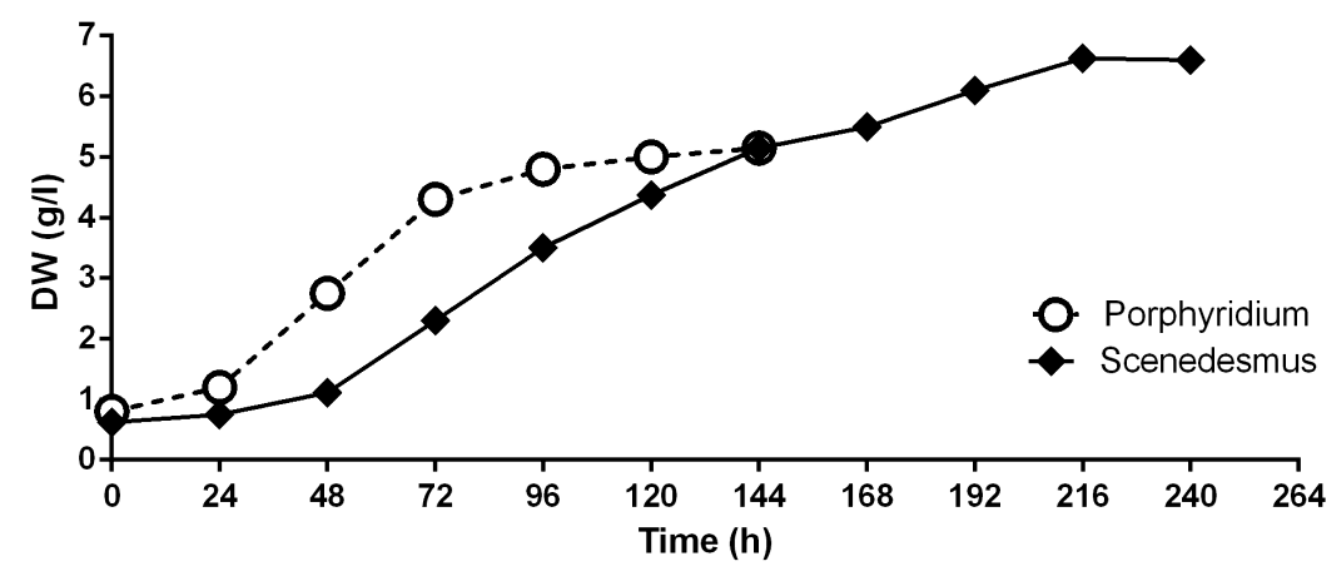

Figure 1. Growth of Porphyridium cruentum and Scenedesmus sp. BGP at intensive conditions for $144 \mathrm{~h}$.

The growth of Scenedesmus sp. BGP started with a short lag phase (Figure 1). After that it continued with a rapid exponential phase between the $48^{\text {th }}$ and $144^{\text {th }}$ hour when it slowed down but reached the maximal yield of $6.6 \mathrm{~g} / \mathrm{l}$ on the $216^{\text {th }}$ hour after which the culture entered stationary phase.
Extracellular polysaccharide production of Porphyridium cruentum Our results for polysaccharide production of Porphyridium cruentum, presented on Figure 2, showed that the viscosity grew from $1.8 \mathrm{mPa} . \mathrm{s}(0 \mathrm{~h})$ to 5 $\mathrm{mPa} . \mathrm{s}$ at the end of the experiment (144h).

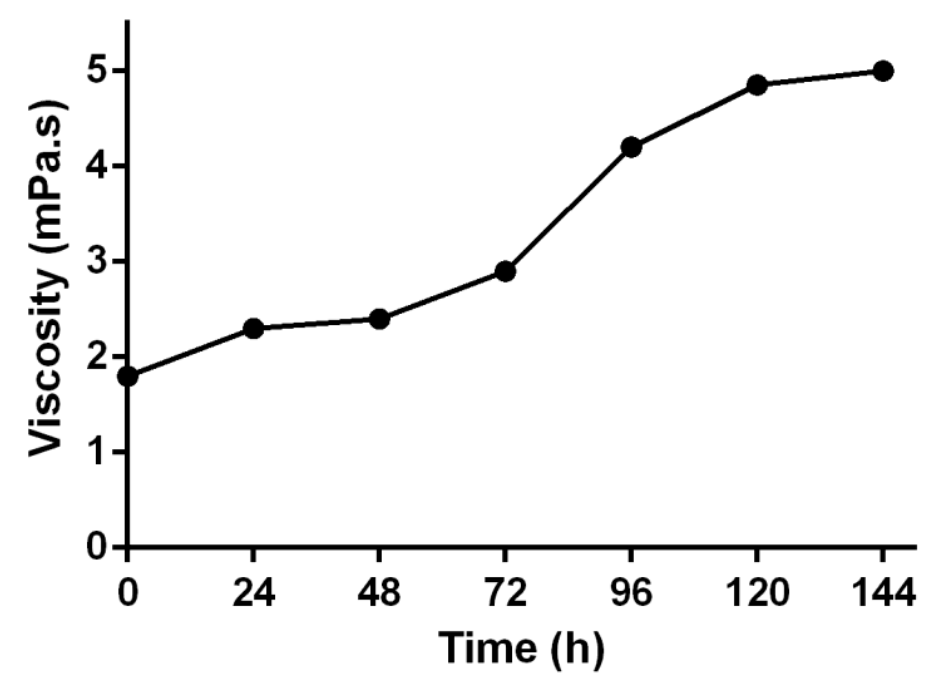

Figure 2. Extracelular polysaccharide production of Porphyridium cruentum at intensive conditions.

\section{Biochemical characteristics of Porphyridium} cruentum and Scenedesmus sp. BGP

Table 3. Biochemical characteristics of two species of microalgae depending on the growth conditions.

\begin{tabular}{|l|c|c|}
\hline Biochemical components & $\begin{array}{l}\text { Percent from dry weight } \\
\text { Porphyridium cruentum }\end{array}$ \\
\hline Proteins & $27-38 \%$ & $24-45 \%$ \\
\hline Lipids & $9-12 \%$ & $23 \%$ \\
\hline Carbohydrates & $40-57 \%$ & $25-28 \%$ \\
\hline
\end{tabular}


VASILEVA IV., et al.

The results revealed that the protein content of Porphyridium reached up to $27-38 \%$ on the 120h (Table 3). Scenedesmus sp. BGP revealed high values in the range of $24-42 \%$ during the different growth phases (Table 3).

The accumulated quantity of carbohydrates under intensive cultivation of $P$. cruentum was between $40-57 \%$ of DW (Table 3). The other microalgae - Scenedesmus sp. BGP also produced this biochemical component in the range of 38-45\% (Table 3).
Our results revealed that lipid content of $P$. cruentum is between 9-12 \% (Table 3). Scenedesmus sp. BGP showed ability to produce a better amount of lipids - around $23 \%$ that changed with less than $1 \%$ during the cultivation (Table 3).

The alga $P$. cruentum accumulated large amounts of fatty acids (Table 4), especially

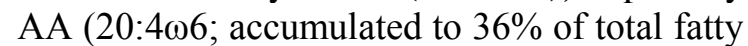
acids) and noticeable amounts of EPA (20:5 (21). Scenedesmus $s p$. is rich in oleic and linoleic acids (Table 4, 22).

Table 4. Fatty acids composition of Porhyridium cruentum and Scenedesnus sp. (22).

\begin{tabular}{|l|c|c|}
\hline Fatty acids\% of Lipids & Porphyridium cruentum & Scenedesmus $\boldsymbol{s} \boldsymbol{p}$. \\
\hline 16:0 palmitic acid & $27-32$ & 30.3 \\
\hline 16:1 palmitoleic acid & $0.3-1.8$ & 6.5 \\
\hline 18:1 oleic acid & $0.6-1$ & 17.5 \\
\hline 18:2 linoleic acid & $4-8.3$ & 21.1 \\
\hline 20:2 eicosadienoic acid & $0.6-1.2$ & 0.3 \\
\hline 20:4 arachidonic acid & $13-29$ & - \\
\hline 20:5 eicosapentaenoic acid & $24-25$ & 0.8 \\
\hline
\end{tabular}

\section{DISCUSSION}

The growth rate of both microalgae was almost the same $([\mu]=0.27$ and $[\mu]=0.31)$. They showed fast adaptation to the growth conditions and sufficient biomass accumulation was observed. In general, the data for the biochemical composition of Porphyridium cruentum were similar to those obtained by (23). The carbohydrate content can be increased after different modifications (24). Our results showed that the cultivation of both microalgae as perspective producers of carbohydrates is in order. Some authors obtained larger amounts of lipids up to $19 \%$ (Table 3) (11). Although the percent of lipids in the Porphyridium cells is not very high, the qualitative composition (polyunsaturated fatty acid) is what makes the lipid content of this red alga extremely valuable for the food industry.

When it comes to Scenedesmus sp. BGP, the strain showed to be a better producer of protein than S. obliquus and S. dimorphus (6-18\%) (25). The produced amount of protein from our strain in up to $45 \%$, which creates a field for perspective potential application of this alga as an unconventional source of protein. From other microalgae from Scenedesmus sp. ( $S$. obliquus and $S$. dimorphus) were extracted 6$14 \%$ lipids $(23,6)$, which is less than what Scenedesmus sp. BGP is able to produce. This stable biochemical composition combined with higher amount of produced proteins than in other microalgae from the same genus, made the strain desirable for biotechnological studies.

The principal use of oleic acid as a component in many foods, is in the form of its triglycerides. It is a component of the normal human diet as a part of animal fats and vegetable oils. Linoleic acid is an essential fatty acid that must be consumed for proper health. A diet only deficient in linoleate (the salt form of the acid) causes mild skin scaling, hair loss and poor wound healing in rats (26). It is of a paramount importance to optimize the growth conditions of microalgae to maximize EPA and AA production (27).

AA and EPA were the dominating polyunsaturated fatty acids (PUFAs) in $P$. cruentum. Nutritionally, EPA (20:5) is one of the most important fatty acids belonging to this group. These long chain omega-3 fatty acids provide significant health benefits to the human population, particularly in reducing cardiac diseases, stroke and high blood pressure, depression, rheumatoid arthritis, and asthma. They have also been reported to inhibit tumor growth (28).

Currently, the sulphurized polysaccharides (EPS) have received much attention due to 
their antibacterial, anti-oxidative, and anticancer properties (29). During cultivation, the cells of Porphyridium cruentum excreted EPS, which caused the cultures to become viscous, which would have been more visible under limiting conditions. Since EPS are released into the culture medium, they can easily be recovered and purified (30). The results were confirmed by (31), who established that viscosity increase at the end of the exponential phase. They also found out that the amount of polysaccharide depends on the intensity of the light.

\section{CONCLUSION}

Microalgae provide numerous opportunities for developing healthier food products.

As the research showed, both of the strains have balanced biochemical content which proves them to be important sources of functional ingredients that could be successfully used as food additives together or separately.

\section{REFERENCES}

1. Gouveia, L., Batista, A.P., Sousa, I., Raymundo, A. and Bandarra N.M., Microalgae in novel food products. In: Papadoupoulos K, Food chemistry research developments. Nova Science Publish, New York, NY, USA, 2008.

2. Spolaore, P., Claire, J. C., Elie, D. and Arsene, I., Commercial applications of microalgae. J Biosci \& Bioeng, 101(2):8796, 2006.

3. Becker, W., Microalgae in human and animal nutrition. In: Richmond A. (Ed.), Handbook of microalgal culture: Biotechnology and applied phycology. Blackwell Science Ltd., Oxford, UK, pp. 312-351, 2004.

4. Soletto, D., Binaghi, L., Lordi, A., Carvalho, J. and Converti, A., Batch and fedbatch cultivations of Spirulina platensis using ammonium sulphate and urea as nitrogen sources. Aquacult, 243(1):217224, 2005.

5. Geldenhuys, D. J., Walmsley, D. J. and Tofrien, D. J., Quality of algal material produced on a fertilizer-tap water medium in outdoor plastic enclosed systems. Aquacult, 68(2):157-164, 1988.

6. Batista, A. P., Bandarra, N., Raymundo, A. and Gouveia L., Microalgae biomass-a potential ingredient for the food industry. EFFoST/EHED Joint Conference. Lisbon, Portugal, 2007.
VASILEVA IV., et al.

7. Chacón-Lee, T. L. and González-Marino, G. E., Microalgae for healthy foods Possibilities and challenges. Compr Rev Food Sci Food Saf, 9:655-675, 2010.

8. Ramus, J., Kenny B. E. and Shaughnessy E. J., Drag reducing properties of microalgal exopolymers. Biotechnol Bioeng, 33:550556, 1989.

9. Arad, S. M., Red Microalgae: Potential Nutraceuticals. Invited lecture at Food in the New Era, Israel, 2009.

10.Dvir, I., Stark A.H., Chayoth, Z., Madar, S. and Arad, S., Hypocholesterolemic effects of nutraceuticals produced from the red microalga Porphyridium sp. Nutr, 1:156167, 2009.

11.Oh, S.H., Han, J.G., Kim, Y., Ha, J. H., Kim, S. S., Jeong, M.H., Jeong, H. S., Kim. N. Y., Cho. J. S., Yoon, W. B., Lee, S. Y., Kang, D. H. and Lee, H. Y., Lipid production in Porphyridium cruentum grown under different culture conditions. $J$ Biosci Bioeng, 108(5):429-34, 2009.

12.González-Fernández, C., Ballesteros, M., Linking microalgae and cyanobacteria culture conditions and key-enzymes for carbohydrate accumulation. Biotechnol Adv, 30:1655-1661, 2012.

13.Apt, K. E. and Behrens, P.W., Commercial developments in microalgal biotechnology. J Phycol, 35:215-226, 1999.

14.Šetlik, I., Ann. Rep. Algol. for the Year 1966. Trebon, CSAV, Inst. Microbiol., pp. 89-100, 1967.

15.Georgiev, D., Dilov, H. and Avramova, S., Millieu nutritif tamponne et méthode de culture intensive des microalgues vertes. Hydrobiol, 7: 14-23, 1978.

16.Jones, R., Speer, H. and Kury, W., Studies on the Growth of the Red Alga Porphyridium cruentum. Physiol Plant, 16: 636-643, 1963.

17.Lowry, O., Rosenbrough, N., Farr, A. and Randball, R., Protein measurement with the Folin phenol reagent. $J$ Biol Chem, 193:265-275, 1951.

18.Petkov, G. and Dilov, H., On the composition of alcoholic extract of microalgae of the Scenedesmus meyen. Hydrobiol, 29:41-44, 1987.

19.DuBois, M., Gilles, K., Hamilton, J., Rebers, P. and Smith, F., Colorimetric method for determination of sugars and related substances. Anal Chem, 28(3):350356, 1956.

20.Ren, H., Lui, B., Ma, C., Zhao, L. and Ren, N., A new lipid-rich microalga 
Scenedesmus sp. strain R-16 isolated using Nile red staining: effects of carbon and nitrogen sources and initial $\mathrm{pH}$ on the biomass and lipid production. Biotechnol Biofuels, 6:143, 2013.

21.Servel, M.O., Claire, C., Derrien, A., Coiffard, L. and Deroeckholtzhauer, Y., Fatty acid composition of some marine microalgae. Phytochem, 36:691-693, 1994.

22.Jena, J., Nayak, M., Panda, H., Pradhan, N., Arika, C. S., Ku, P., Rao, B., Prasad, R. and Sukla L., Microalgae of Odisha Coast as a Potencial Source for biodiesel production. World Env, 2(1):11-16, 2012.

23.Becker, W., Microalgae biotechnology and microbiology. Cambridge University Press, Cambridge, UK, 1994.

24.Markou, G., Angelidaki, I. and Georgakakis, D., Microalgal carbohydrates: An overview of the factors influencing carbohydrates production, and of main bioconversion technologies for production of biofuels. Appl Microbiol Biotechnol, 96:631-645, 2012.

25.Sydney, E.B., Sturm de Carvalho, W., ThomazSoccol, V., Larroche, Pandey, A., Soccol, C.R., Potential carbon dioxide fixation by industrially important microalgae. Bioresour Technol, 101(15):5892-5896, 2010.

26.Ruthig, D.J. and Meckling-Gill, K. A., Both (n-3) and (n-6) fatty acids stimulate wound
VASILEVA IV., et al.

healing in the rat intestinal epithelial cell line, IEC-6. J Nutr, 129(10):1791-1798, 1999.

27.Asgharpour, M., Rodgers, B. and Hestekin J. A., Eicosapentaenoic Acid from Porphyridium cruentum: Increasing Growth and Productivity of Microalgae for Pharmaceutical Products. Energ, 8:1048710503, 2015.

28. Patil, V., Källqvist, T., Olsen, E., VogtHans, G. and Gislerød, R., Fatty acid composition of 12 microalgae for possible use in aquaculture feed. Aquacult Internat, 15(1):1-9, 2007.

29.Sun, L., Wang, L. and Zhou, Y., Immunomodulation and antitumor activities of different molecular weight polysaccharides from Porphyridium cruentum. Carbohydr Polym, 87:12061210, 2012.

30. Bafanaa, A., Characterization and optimization of production of exopolysaccharide

fromChlamydomonas reinhardtii. Carbohydr Polym, 95:746-752, 2013.

31. Arad, S. M., Adda, E. and Cohen, Z., The potential production of sulphated polysaccharides from Porphyridium. Plant Soil, 89:117-127, 1985. 